\title{
REDE É UM MONTE DE BURACOS, AMARRADOS COM BARBANTE
}

\section{NETWORK IS A LOT OF HOLES TIED BY STRINGS}

\author{
Fernanda Otoni de Barros-Brisset ${ }^{1}$
}

Fernanda Otoni de Barros-Brisset. Rede é um monte de buracos amarrados com barbante. Rev Bras Crescimento Desenvolv Hum. 2010; 20(1): 83-89

\section{Resumo:}

O presente artigo apresenta a crítica dos mecanismos que sustentam e fazem funcionar o manicômio judiciário. Propõe a superação dessa instituição a partir da montagem de uma rede intersetorial aberta na cidade, considerando a capacidade e responsabilidade desses sujeitos, designados loucos infratores.

Palavras-chave: louco infrator; manicômio judiciário; política de rede intersetorial; responsabilidade; PAI-PJ.

\section{Abstract:}

The present article proposes a criticism of the mechanism to maintain the criminal lunatic asylum. It proposes the superation of this institutionthrough the association of a cross sector network opened in the city, considering the capacity and the responsibility of those subjects mentioned as psychotic criminals.

Key words: psychotic criminal; criminal lunatic asylum; cross sector network policies; responsibility; PAI-PJ

ROSA, João Guimarães. “Aletria e Hermenêutica”. In: Tutaméia (terceiras estórias). 6ª ed. Rio de Janeiro: Nova Fronteira, 1985. p.14.

1 Psicanalista (EBP/AMP). Doutora em Ciências Humanas: Sociologia e Política (UFMG). Coordenadora Clinica do Programa de Atenção Integral ao Paciente Judiciário (PAI-PJ-TJMG). Professora do Departamento de Psicologia e Direito da PUCMinas. Contato: fernanda.otoni@terra.com.br 
Belo Horizonte é uma grande cidade, estando entre as quatro maiores cidades do Brasil. Ali não existe manicômio judiciário e, de modo geral, há 10 anos os portadores de sofrimento mental que cometem crimes naquela cidade não são enviados para o Manicômio Judicial de Barbacena. As instituições da cidade, que cuidam destes casos, produziram entre si um acordo, assumindo o compromisso e a responsabilidade no desenvolvimento de uma política intersetorial de atenção integral ao louco infrator, cujo acompanhamento jurídico, clínico e social acontece na rede aberta da cidade, no sistema SUS, segundo a orientação da lei 10216/ 2001, sem dispensar o dever de cada um de responder por seu ato diante da lei., ${ }^{1,2,3}$

A gestão desta política, feita por vários, acontece através de um dispositivo conector, que articula as ações dos operadores do direito com os equipamentos da rede pública municipal em saúde mental e da assistência social, tendo por orientação a singularidade clínica, social e jurídica do sujeito portador de sofrimento mental. Este dispositivo é o PAI-PJ, um programa de atenção integral ao paciente judiciário portador de sofrimento mental infrator, do Tribunal de Justiça de Minas Gerais.

Em Belo Horizonte não precisamos mais desta estrutura manicomial judiciária, pois esta foi substituída por uma rede intersetorial que funciona desde o início do processo criminal; esta rede se encontra articulada com o PAI-PJ que, além de secretariar o sujeito no acesso aos recursos sociais e clínicos, também auxilia o Juiz, seja de conhecimento ou da execução, no acompanhamento destes casos desde o primeiro momento em que entram no sistema jurídico. ${ }^{4,5}$

Não estamos entre aqueles que acreditam que a superação do modelo do manicômio judiciário tem seu inicio somente após ter sido decretada a sentença de medida de segurança. Se quisermos, de fato, desconstruir este dispositivo medieval, não podemos continuar alimentando sua estrutura, fazendo entrar novos corpos na boca sem fundo da solução penal;
Trabalhamos desde a entrada do sujeito no sistema jurídico, estamos ali acolhendo-o na porta de entrada. ${ }^{1,2}$

Ali nos colocamos ao lado dele, pois este tem o direito de assistência em saúde mental e deve ter ao seu alcance o acompanhamento necessário para o seu sofrimento. E serão os detalhes de sua trajetória na rede de social e de tratamento, bem como as respostas que construirão na relação com o sistema de justiça que irão subsidiar o acompanhamento jurídico, clínico e social de cada caso, no desenho de sua medida.

Nosso compromisso é ético e político, orientado por 10 anos de experiência com mais de 700 casos e mil processos acompanhados. Não nos alinhamos com aqueles que acreditam que é possível construir uma solução humanizada para os manicômios, uma política de saúde mental para estas instituições. Mas estamos convencidos que temos a necessidade de construir uma política de atenção integral ao louco infrator, conforme os princípios da lei $10216 / 2001 .^{4}$

Vou dizer por que insisto nisto. Atualmente, desde 17 de julho deste ano, o TJMG junto com a Secretaria Estadual Saúde assumiu o compromisso de desospitalização dos pacientes judiciários do Manicômio Judiciário de Barbacena. Esta instituição abriga, hoje, duzentos e noventa pacientes, cuja média de internação tem sido de 20 anos; 30\% já poderiam sair, pois estão com laudo de cessação de periculosidade assinado, mas não tem para onde ir.

Outros estão por lá, há muitos anos, tendo como único modo de tratamento, algumas oficinas internas, medicação e muitos senões. Outros acabaram de chegar de outras comarcas do Estado e chegam já com o recado que a passagem é sem volta! Não imagino que esta realidade seja diferente daquela do resto do país. Outros poderiam até voltar para casa, não precisam em nada daquele lugar, mas inexplicavelmente continuam, até não poderem 
mais retornar. Esta deve ter sido a situação que aconteceu com muitos dos que hoje não tem mais lugar neste mundo, a não ser aquele. Esta tem sido a trajetória, há uns 150 anos... em qualquer manicômio judiciário do nosso pais. Boca sem fundo, viagem de ida sem bilhete de volta, na maioria dos casos.

A equipe técnica que trabalha neste estabelecimento deu depoimentos contundentes de seu aprisionamento à um equipamento sem vida, sem saída, sem solução! Estamos agora juntos, na tarefa de abrir as portas, para fazer com que a vida passe a circular com ares de liberdade arejando os espaços abafados da segregação. Pois é consenso que os pacientes encontram-se enclausurados numa estrutura sem comunicação, sem porosidade, esvaziada de vida criativa... Vivendo de passado, sem perspectiva de pro-jetar, sem projeto futuro!

Hoje temos pela frente um trabalho duro de inventar saídas inéditas, reconstruir os laços destroçados ainda passíveis de algum tratamento e quando não for possível o redesenho de laços antigos, buscarem os meios para criar novos laços com a vida na cidade. Sensibilizar comunidades e redes de saúde dos outros municípios do estado será o trabalho dos próximos meses que temos pela frente, nosso horizonte; estamos orientados quanto ao esforço para desconstruir a lógica da segregação que é o sentido cotidianamente mantido e alimentado pela continuidade e existência desta estrutura manicomial.

Sempre achei que não precisávamos de Manicômios Judiciários para fazer justiça, a experiência do PAIPJ em BH, me dava cotidianamente elementos para acreditar nisto. Hoje tenho certeza que não precisamos desta estrutura! Para que serve um manicômio judiciário? Para quem serve o Manicômio Judiciário? Não encontraremos razões para sustentação deste monumento, não no campo dos direitos humanos, da lei 10216 ou da saúde mental. Suas razões talvez se mostrem em outras sea- ras, mas com certeza onde encontrarmos a razão da manutenção do manicômio judiciário, não encontraremos o sujeito e o campo dos direitos.

Por isto sustentar, apoiada pela nossa experiência, que temos que construir uma política nacional de atenção integral ao louco infrator e se existe uma política para os manicômios judiciários é aquela que deve se dirigir radicalmente no sentido da sua superação. Hoje já temos ao nosso alcance os dispositivos clínicos, jurídicos e sociais para caminharmos seguros nesta direção! Não existe isto de melhorar a estrutura internamente, humanizar o tratamento da internação. Ora, temos é que abrir as suas portas, pois a humanidade está incluída é na vida que palpita fora dos campos de exclusão.

Em 2002, no I encontro de reorientação dos hospitais de custodia e tratamento, ficou acordado que não seriam construídos mais manicômios judiciários neste país e caminharíamos no sentido da desconstrução dos que existiam, visando alcançar, num horizonte possível, sua substituição.

Hoje assistimos à criação no campo da saúde de uma unidade experimental de saúde para contenção de adolescentes que não mais podendo responder pela medida sócio-educativa de internação, supondo sua altíssima periculosidade, encontrou nesta solução um modo de perpetuar seu isolamento social. Dizem os gestores que esta foi uma saída humanizada, moram em casas pequenas, bem equipadas (guardadas e vigiadas), foram para estas casinhas através de uma medida de internação compulsória, prolatada em sentença de vara cível, e o que é o pior, sob o argumento de ter esta ação sido sustentada na lei 10216/2001.

O mito da periculosidade sustenta estes e outros absurdos, aqueles que crêem em monstros possuídos por indescritível e inimaginável patologia mental. $5,6,7$

Não será no manual da patologia, no manual dos inquisidores, que encontraremos 
as respostas através de tecnologias medievais. Se quisermos tentar alcançar alguma saída deste sistema antigo e obscuro, devemos buscar desenhá-la no acompanhamento das biografias e para isto precisamos dispensar o isolamento e investir na convivência, no acompanhamento, nas soluções de sujeito, suas pequenas invenções para tratar seu sofrimento mental.

Hoje levanta-se um discurso, em geral, de que o tratamento em saúde mental serve para os psicóticos, esquizofrênicos, paranóicos, talvez... Contudo, os manicômios devem ser mais bem equipados de acordo com as novas tecnologias de tratamento, pois esta estrutura ainda se justifica no caso das psicopatias, dos transtornos de personalidade, daqueles que tem a parte frontal do cortex atrofiada, daqueles sem sentimento de culpa, dos casos graves de retardo mental. Se voltarmos no tempo escutaremos sua justificação pelos casos dos monomaníacos homicidas, na voz de Esquirol, e daqueles com as mentes perigosas, os homens delinquentes, com os olhos oblíquos e as grandes mandíbulas proeminentes e a boca grande...

Ai!! Acho que chegamos... nas historias de lobo mau! Sim, viver é arriscado, viver é muito perigoso, dizia o jagunço Riobaldo do Grande Sertão Veredas! E seguimos navegando por estas veredas, pois com Pessoa sabemos que “navegar é preciso, viver não é preciso”! É arriscado, não existe vida sem risco! Porém, os sonhos de uma sociedade de controle continuam e ganham força nos dias que correm desavisados que sempre existe o despertar.

Vejam a época desta semana, 11 de setembro! Dedicou 11 das suas páginas tentando descrever e controlar os destinos de um criminoso. Inúmeros são os relatórios médicos e metodologias para acercar sobre sua periculosidade. São muitos e cada um em um sentido! Mares turbulentos os da metodologia cientifica, cada um surfando na sua onda, cada hora é uma que vem e vai... E o mar, continua por ali; indecifrável, inominável, um universo de possibilidades.
No PAI-PJ nós não trabalhamos com pericia. Fazemos os acompanhamentos, que levam alguns anos. Quando começamos a acompanhar um caso não temos a menor idéia para onde ele pode nos levar. Mas ficamos ali, do lado, secretariando a sua trajetória! Tenho para dizer pra vocês, que neste universo de milhões de habitantes, nos últimos dez anos, passaram pela comarca de $\mathrm{BH}, 1058$ processos de pessoas que cometeram crimes, exatamente 755 pessoas. Estes casos receberam durante o tempo de sua permanência no sistema de justiça, da entrada do processo na fase de instrução até a sua liberação, inúmeros diagnósticos, muitos foram anexados aos processos. Qualquer um pode fazer uma pesquisa nos processos destes casos e vão encontrar laudos diversos. Até hoje eu não encontrei nenhum caso onde todos os laudos coincidem em seu parecer.

Rapidamente percebemos que não podemos nos fixar na determinação do diagnostico pericial para desenharmos as estratégias de nossa caminhada, ao lado destes sujeitos, na direção dessa embarcação. Estamos entre aqueles que apostam que essa barca tem que ter uma direção, não pode seguir à deriva nesse mar de especulações diagnósticas.

Nossa bússola então se encontra no bolso do sujeito, continuamos acompanhando seu caminho, sua trajetória, suas soluções para tratar seu sofrimento, suas pequenas invenções no trato com a cidade e em seu tratamento na rede de saúde. E neste caminho vamos observando a paisagem e testemunhamos que os diagnósticos dos peritos mudam com o tempo, de acordo com o momento do sujeito.

Como a perícia não acompanhou o momento do ato, o que lhes resta fazer é presumir; presumem a periculosidade do indivíduo, relacionando o motivo do ato com a patologia correspondente a seu tipo clínico, já minuciosamente descrito nos manuais de psiquiatria forense. As potencialidades de resposta do sujeito não entram pela sala de atendimento, 
ficam do lado de fora, ali importa apenas o instante do ato, o crime e a relação de causalidade estabelecida entre o estado patológico do sujeito como situação que deu causa ao seu ato. Este parecer encerra o laudo pericial! Geralmente, neste momento vários laudos de psiquiatras já trafegam no processo, não apenas o da perícia oficial. Com base nisto o Juiz estabelecerá uma medida de segurança, por tempo indeterminado, até cessar sua periculosidade, pressuposta pela sua condição patológica, sua doença mental.

O PAIPJ continua acompanhando, vamos caminhando, passando por esse oceano abismal e incerto dos diagnósticos psicopatológicos e seguindo o horizonte que aponta a trajetória do sujeito. Aprendemos que entre o louco e o infrator, entre o paciente e o judiciário, existe um sujeito indefinível, com potencialidades inéditas, para além da nomeação cientifica que o encerra.

Seguir suas pistas, estamos seguros, nos pode levar a algum lugar. E para isto o acompanhamento é fundamental, se colocar ali ao lado, secretariar o sujeito nas soluções que inventa para desenrolar-se dos embaraços que a angústia lhe causa. Soluções de vida para o sofrimento e não encerrar sua vida no formalismo do diagnóstico, palavra morta!

No lugar da presunção da periculosidade, trabalhamos, desde o princípio, com a presunção de sociabilidade e isto faz toda diferença. Esta aposta é o que permite que, mais adiante, outros laudos possam vir a dizer outras coisas, outras teorias, outras apostas, menos assustados com a periculosidade evidente e mais favorável ao laço social. ${ }^{8}$

Com isto, desde o princípio, através deste dispositivo conector, quando chega um caso, ainda no inicio do processo criminal, acolhemos, escutamos e encaminhamos para a rede pública de saúde para seu tratamento, levantamos as possibilidades de ampliação dos laços de sociabilidade na rede de assistência social da cidade, orientamos o sujeito em relação às conseqüências jurídicas de seu processo que terá que responder. O processo segue seu curso, caminha ao lado. O juiz e promotor acompanham a trajetória do sujeito através do acompanhamento cotidiano do PAI-PJ. Se a perícia indicar sua insanidade mental, o sujeito receberá uma medida de internação ou ambulatorial, de acordo com o crime que cometeu. Continuamos acompanhando as respostas do sujeito à resposta jurídica, ao seu tratamento e sua relação com a cidade. Recebeu uma medida ambulatorial: tratamento na rede pública de saúde. Se for uma medida de internação: rede publica de saúde, também!

De tal sorte que, seguindo estas brechas jurídicas e as pistas de sujeito, os pacientes judiciários alcançam a possibilidade de demonstrar sua capacidade de responder pela sua medida em liberdade, quando sua medida de internação é modulada para ambulatorial. Hoje, dos 266 casos atualmente em acompanhamento, 241 casos cumprem sua medida no modo ambulatorial ou estão na fase de instrução ainda.

Vamos acompanhando, e neste caminho, a periculosidade vai se apagando em cada caso e ganhando cor uma responsabilidade inédita, uma sociabilidade razoável, uma vida que se abre para um projeto de possibilidades, construindo sua medida, na medida do possível para cada um, sem dispensar sua obrigação de responder pelo que do seu jeito escapou fora da lei dos homens.

E os casos impossíveis, perigosos, ameaçadores? Vamos combinar! É o diagnóstico! Contudo no acompanhamento, com a convivência, nos aproximamos de sua humanidade razoável, de tal sorte que afirmamos que "não existe nada mais humano que o crime!”

É isto que a nossa experiência tem pra contar. Em BH, contamos com um Tribunal de Justiça, um Ministério Público e uma Defensoria Pública que decidiram que a questão do louco infrator é um compromisso de toda sociedade e que cabia aos operadores do direito seguir o que manda a lei, mas que a solução do 
problema não se encerrava na letra fria da lei, precisava seguir o que a experiência em saúde mental ensinava, desde os tempos basaglianos, a saber: dispensar a referência lombrosiana. Para tanto apostou num dispositivo conector entre a justiça e a saúde, criando um órgão auxiliar para realizar o acompanhamento destes casos, responsável pelo encaminhamento e acompanhamento destes pacientes judiciários na rede SUS - criou-se o PAI-PJ.

Mas sobretudo e fundamentalmente, Belo Horizonte tem uma rede municipal de saúde mental que funciona de um modo complexo, muitas vezes tenso e constrangido, mas é uma montagem viva, que suporta o risco como é possível. Nesta rede tem cabimento o tratamento do louco infrator em qualquer fase do processo, sem recuar diante do seu compromisso com a invenção de soluções razoáveis no tratamento do sofrimento mental. ${ }^{9}$

Afinal, sabemos que se nestes 10 anos estivéssemos ainda encaminhando esta demanda (755 casos) para o Manicômio Judiciário, ou teríamos construído alguns outros, pelo menos mais três, ou os pacientes estariam nas cadeias e prisões à espera de vaga. E provavelmente passariam no mínimo 20 longos anos, antes que eles pudessem ver a vida outra vez... Uma vida que já seria outra, sua rede de sociabilidade talvez não existisse mais e enfim, teria sido expulso da órbita da humanidade por ser simplesmente o que é: um sujeito, com um jeito louco, mas humano de ser!

Nestes 10 anos, a média de tempo de acompanhamento pelo PAI-PJ, da entrada no programa, ou seja, antes mesmo da sentença, até a cessação de sua periculosidade, tem sido de cinco anos, sendo acompanhado no espaço aberto da cidade, por uma rede em movimento, ligado na vida! Cada um segue enlaçado pelas suas dificuldades, embaraços e soluções de seu laço social na rede viva da cidade. Será que não temos aqui, uma demonstração inequívoca que temos os elementos para apostar numa política de atenção integral ao louco infrator, em substituição à uma política para manicômio judiciário?

Contudo, estamos cientes de que não existe uma receita de bolo. Cada cidade deverá tomar para si o dever de se apropriar dessas referências para integrá-las e ajustá-las ao contexto e aos recursos locais dispostos naquele território. A reforma necessária e desejável deve acontecer no município do portador de sofrimento mental, pois lá estão os elementos que dão suporte à sua rede de sociabilidade. Mas tem que ter rede, não é mesmo? Enfim, a experiência transmitida no encontro com os portadores de sofrimento mental que cometeram algum crime não nos permite recuar diante da necessidade de reunir os diversos atores e construir diretrizes nacionais para a construção de uma política de atenção integral ao paciente judiciário, portador de sofrimento mental infrator, na rede publica de saúde e nos espaços abertos de convivência da cidade.

Não é simples, a solução será sempre alcançada no campo da complexidade. Não é fácil! Mas é possível. No lugar de uma medida de segurança, apostamos que o que segura cada um é o suporte de uma rede, e como diz Guimarães Rosa: Rede é um monte de buracos amarrados com barbante! E eu vou ficando por aqui. 


\section{REFERÊNCIAS:}

1. Barros-Brisset, FO. Gênese do conceito de periculosidade (Tese de doutorado). Belo Horizonte: UFMG. 2009

2. Barros-Brisset, FO. Por uma política de atenção integral ao louco infrator. Contribuições a partir da experiência do PAI-PJ. Belo Horizonte: TJMG. 2009

3. Basaglia, F. A Instituição Negada. Rio de Janeiro: Graal,. 2001.

4. Foucault, M. Os Anormais. São Paulo: Martins Fontes, 2001.

5. Garcia, C. A clinica do social. Belo Horizonte: Editora Projeto. 2000.
6. Jornal do Federal. Manicômio Judiciário... o pior. Brasília: CFP. 2000.

7. Miller, J-A. Rien n'est plus humain que le crime. Paris: ECF. Revue Mental, 2008. n. 21.

8. MINISTÉRIO DA SAÚDE/ MINISTÉRIO DA JUSTIÇA. Seminário Nacional de Reorientação dos Hospitais de Custódia e Tratamento Psiquiátrico: Relatório Final. Brasília:. setembro de 2002.

9. Rosa, J. G. Tutaméia. Rio de Janeiro: Nova Fronteira, 1985.

Recebido em 22 de agosto de 2009. Modificado em 02 de janeiro de 2010. Aceito em 30 de janeiro de 2010. 